\title{
FACTORS ASSOCIATED WITH TOBACCO SMOKING AND THE BELIEF ABOUT WEIGHT CONTROL EFFECT OF SMOKING AMONG HUNGARIAN ADOLESCENTS
}

\author{
Melinda Pénzes ${ }^{1}$, Edit Czeglédi², Péter Balázs ${ }^{1}$, Kristie L. Foley ${ }^{3}$ \\ ${ }^{1}$ Institute of Public Health, Faculty of Medicine, Semmelweis University, Budapest, Hungary \\ ${ }^{2}$ Doctoral School of Psychology, Eötvös Loránd University, Budapest, Hungary \\ ${ }_{3}^{3}$ Medical Humanities Program, Davidson College, Davidson, NC, USA
}

\section{SUMMARY}

Introduction: The relationship between body weight and smoking has been well-documented among adult populations, but the data among youth are inconsistent. This study explores the relationship among social, behavioural, body weight-related factors and adolescent smoking while identifying factors associated with the belief that smoking controls weight.

Materials and methods: Baseline data from a three-year, prospective cohort study started in 2009 in Hungary's six metropolitan cities. Randomly selected 6th and 9th grade students completed a self-administered questionnaire during the 2009-2010 school year ( $n=1445 ; 45 \%$ boys, mean age of 6th graders: 12.06 years, $S D=0.63$; mean age of 9 th graders: 15.06 years, $S D=0.63)$. Calculations of Body Mass Index (BMI) were based on objectively measured weight and height data of participants. Appetite-Weight Control Scale of the Short Form of Smoking Consequences Questionnaire was used to measure the belief that smoking supports weight control. Bivariate and multivariate logistic regression analyses were performed to examine the association between the perception of weight control and smoking, while controlling for potential confounding variables (e.g., gender).

Results: $24.8 \%$ of participants smoked cigarettes within the past 30 days. The odds of smoking were increased among students who were older, had smoking friends, were exposed to parental smoking, and had poorer academic performance. BMl showed positive association with smoking (increases in BMl were associated with higher odds of smoking), and the belief that smoking controls weight mediated this association. There was no difference in smoking prevalence among those motivated either to lose or gain weight ( 30\%), but was considerably lower among adolescents satisfied with their body weight (19\%). The belief that smoking supports weight control was more common for girls, older students, and those who perceived themselves as overweight.

Conclusions: Dissatisfaction with body weight and the belief that smoking has weight controlling effects are associated with an increased likelihood of adolescent smoking, therefore they must be considered in smoking prevention programmes among youth.

Key words: smoking, adolescence, weight control belief, BMI, perceived body shape

Address for correspondence: M. Pénzes, Semmelweis University, Faculty of Medicine, Institute of Public Health, Nagyvárad tér 4. Budapest, H-1089, Hungary. E-mail: penmel@net.sote.hu

\section{INTRODUCTION}

Tobacco smoking is the leading preventable risk factor of Disability Adjusted Life Years for Hungarian people (1). According to the latest representative data, the prevalence of current daily smoking is $29.9 \%$ among Hungarian adults between 18 and 64 years of age with an additional $6.2 \%$ of occasional smokers (2). Recent data among youth aged 10-18 suggest that current daily smoking ranges from $21 \%$ to $33 \%$ depending on the age of the target population. Smoking trends have declined in both genders in the recent years, although current smoking among high school girls exceeds the prevalence rates of boys (3-6).

Numerous factors are associated with adolescent smoking including age, parental smoking, parental socioeconomic status, peer smoking, attitudes of family and friends, school factors, risk behaviours, lifestyle, stress, self-esteem, attitudes and health con- cerns (7). A comprehensive review suggests that concerns about weight can also be an important factor for smoking, especially among females (8). In modern societies the thin body ideal, and sociocultural pressures to be thin had a deep impact on the adolescent population; girls, in particular, are often dissatisfied with their body image and perceive themselves as overweight. Dieting and other weight control methods are well-known features of adolescent behaviour to achieve an idealized perfect body shape $(9,10)$. The youth's assumption that tobacco smoking can be used as a weight control method is based on the widespread belief that smoking is an effective weight control strategy although its anorectic effect is slow and may benefit only older individuals (11). The belief that smoking controls weight seems to be agerelated and more pervasive among girls (12-15). There is conflicting evidence on the association between adolescents' body weight and smoking $(8,15)$. The finding of a positive interrelation or no 
relationship between body weight and smoking among youth is inconsistent with findings for adults which have suggested that body weight and current smoking status are inversely associated $(8,15)$. Some studies propose that higher body mass index (BMI) and overweight in adolescence may be related to smoking, but the relationship to gender is inconsistent $(11,15-19)$. Other studies have found negative or no association between BMI and smoking (20-23). Self-perception of body weight may also play a role in initiation and maintenance of smoking (24). Numerous studies indicated that adolescents, especially girls who perceive themselves as being overweight, were more likely to smoke (13, 17, 18, 21, 23-28). Concerns about weight also show a positive relationship with smoking $(19,25,27)$. Weight concerns may be more related to body image or weight perception than to the actual objective weight (15). For females, weight perception is guiding the behaviour of smoking rather than BMI calculated with selfreported data (26). When predicting regular smoking in female adolescents, individuals' self-perception is more important than their actual weight (20). Weight concerns show associations with current smoking or smoking initiation for female adolescents (27, 29). Evidence points most clearly to a positive association between smoking and dieting behaviour (8). Many studies found that girls dissatisfied with their weight and trying to lose weight and/or following specific diet are more likely to smoke (17, 23, 29-32).

This study evaluated the relationships among social, behavioural, body weight-related factors and adolescent smoking and assessed factors associated with the belief that smoking controls weight. The other aim was to explore whether a cognitive factor, namely the belief that smoking supports weight control plays a mediator role in the association between BMI and smoking.

\section{MATERIALS AND METHODS}

Sample: This research was approved by human subjects' review boards at Semmelweis University and Davidson College as a part of a larger study on building capacity for tobacco research in Hungary (1 R01 TW007927-01). The sample consisted of 2,208 6th and 9th grade students participating in the Longitudinal Study of Tobacco Smoking and Weight Management among Adolescents. Our three-year cohort study with yearly data collections started in the 2009-2010 school year in six metropolitan cities. The cluster sampling involved 78 schools including elementary, vocational and high schools. Parents were informed about the research by a passive consent procedure. Subjects' participation was voluntary and all subjects provided written and verbal consent. Trained data collectors unknown to the students asked the participants to complete the questionnaire in the classroom within one class time. Self-reported and measured weight $(\mathrm{kg})$ and height (cm) were available in $65.4 \%$ of the sample. The measurement of students' weight and height was carried out with the assistance of school nurses. Twenty-eight percent of data are missing because the school refused to perform the height and weight measurements and $6.6 \%$ of adolescents either failed to answer the height and weight questions or the values were biologically implausible. Therefore 1,445 students (653 boys and 792 girls, mean age 13.95 years, $\mathrm{SD}=1.58$; mean age of 6 th graders: 12.06 years, $\mathrm{SD}=0.63$; mean age of 9th graders: 15.06 years, $\mathrm{SD}=0.63$ ) comprised the study sample.
Measurement: The participants' height $(\mathrm{cm})$ and weight $(\mathrm{kg})$ without shoes and wearing light clothing were measured by school nurses using standardized equipment and procedures. The Body Mass Index (BMI) was calculated as weight (kg)/height (m) ${ }^{2}$ separately for self-reported and measured data. Although correlations between self-reported and measured weight $(\mathrm{r}=0.96 ; \mathrm{p}<0.001)$, height $(\mathrm{r}=0.94 ; \mathrm{p}<0.001)$ and $\mathrm{BMI}(\mathrm{r}=0.92 ; \mathrm{p}<0.001)$ indicated a high agreement, self-reported BMI of students was less than the actual BMI $\left(\mathrm{t}_{(1444)}=13.155, \mathrm{p}<0.001\right.$; Cohen $\left.\mathrm{d}=0.32\right)$, therefore BMI based on objectively measured height and weight was used for analyses. Age and gender-specific cut-off points for BMI were used to classify underweight, normal weight, overweight and obesity in the sample $(33,34)$.

Self-reported smoking behaviour was assessed by the Hungarian version of smoking-related questions from the Youth Risk Behaviour Survey 2009 (6, 35). In the current analysis, we used two major questions: a) Did you smoke at least one cigarette in the past 30 days, b) and if so, how many? Smoking status was dichotomized into non-smokers who did not smoke during the past 30 days (non-smokers and experimenters combined and coded "0") and smokers who smoked during the past 30 days (intermittent and regular smokers combined and coded "1") (36).

Mother/female guardian and father/male guardian smoking status was also assessed (yes, no) and the items were combined to create a dichotomous variable representing parental smoking $(0=$ none, $1=$ one or both parents $)$.

Students were asked to report how many of their five closest friends smoke at least one cigarette a day. Responses were coded " 0 " (none of them) and " 1 " (one or more friends smoking).

Weight-related smoking expectancies were ascertained by using the Appetite-Weight Control (AWC) Scale of the Short Form of Smoking Consequences Questionnaire (S-SCQ) (37). The AWC Scale included five statements ("Smoking controls my appetite," "Smoking keeps my weight down," "Cigarettes keep me from overeating," "Cigarettes keep me from eating more than I should," and "Smoking helps me control my weight.") and participants were asked to rate the likelihood of each consequence on a 10-point Likert scale from "completely unlikely" to "completely likely" (0-9). The Hungarian version of the S-SCQ was tested on an adolescent sample, and the psychometric properties of the questionnaire were found to be satisfactory, including internal consistencies and factor structure (38). In our sample, internal consistency of this scale was excellent (Cronbach $\alpha=0.91,95 \%$ CI $0.91-0.92)$. The AWC Scale was dichotomized ( $0=$ low agreement; $1=$ high agreement) using median split because the distribution of the scale was deviated from the normal distribution considerably.

Participants were asked about how they perceive their body shape. Response options included "much too thin, a bit too thin, about right size, a bit too overweight and much too overweight". Responses were divided into three categories (thin, about right size, overweight) as "much too" and "a bit too" options were added in the thin and overweight categories (10). A further dichotomous variable was created for logistic regression analyses $(0=$ thin or about right size; $1=$ overweight). Desire to change weight and body shape was assessed with the response options "Yes, I would like to lose weight but I am not on a diet," "Yes, I would like to lose weight and I am on a diet," "Yes, I would like to gain weight," and "No, because my weight is right." For exploring weight management goals three categories were created as respondents 
who reported trying to lose weight with or without diet were collapsed. While analysing dieting behaviour, answer "Yes, I would like to lose weight and I am on a diet" was coded as " 1 " and all the other options were coded as " 0 ".

Self-reported family income was assessed on a 5-point Likert scale ranging from 1 ("very poor") to 5 ("very good"). Responses were dichotomized and coded "1" ("very poor", "poor") and "0" ("average", "good", "very good").

School achievement of respondents in the last semester was inquired about (in Hungary, the best mark is 5, the worst is 1) and dichotomized into "satisfactory" or "worse" $(\leq 3.50)$ coded as " 1 " and "good" $(\geq 3.51)$ coded as " 0 ".

Analysis: Descriptive statistics of all variables in the study were conducted. Chi-square tests and independent samples t-tests were used to compare differences between those who smoked during the past 30 days and who did not, and the differences between genders. The association of smoking in the past 30 days and predictor variables were examined in bivariate and multivariate logistic regression analyses separately by gender. We also conducted these analyses to assess the association of the belief that smoking controls weight and its predictor variables. Unadjusted and adjusted odds ratios with $95 \%$ confidence intervals were calculated for smoking and the belief smoking supports appetiteweight control. Non-smokers and those with low agreement of the belief were used as references. The mediator role of smoking's weight control belief in the association between BMI and smoking was examined with a mediation analysis (39). SPSS 17.0 was used for all statistical analyses.

\section{RESULTS}

Characteristics of the sample: Table 1 shows that $24.8 \%$ $(n=359)$ of respondents smoked in the past 30 days prior to the study. Smoking prevalence was similar for boys and girls $\left(\chi_{(1)}^{2}=1.888, \mathrm{p}=0.169\right)$. The proportion of smokers was much lower among 6 th graders than 9 th graders $(5.6 \%$ vs. $36.2 \%$, respectively; $\left.\chi_{(1)}^{2}=169.737, \mathrm{p}<0.001\right)$. Girls consumed tendentiously less cigarettes on their smoking days than boys $\left(\chi_{(3)}^{2}=6.334, \mathrm{p}=0.096\right)$ Students in 6th grade smoked significantly fewer cigarettes than the 9th grade sample $\left(\chi_{(3)}^{2}=18.763, p<0.001\right)$, however, the proportion of students consuming more than 20 cigarettes was higher among them ( $22.2 \%$ vs. $5.7 \%$, respectively). Half of the participants reported that one or both of their parents were smoking. The rate of parental smoking was similar in both genders $\left(\chi_{(1)}^{2}=1.323, \mathrm{p}=0.250\right)$. One or more close friends' smoking occurred significantly more frequently among girls than boys $\left(\chi_{(1)}^{2}=4.268, p=0.039\right)$. Smoking was typically more prevalent among those who reported poor family income compared to respondents evaluating their family income as average or good ( $31.9 \%$ vs. $24.7 \%$, respectively, $\left.\chi_{(1)}^{2}=2.860, p=0.091\right)$. Students of poor school achievement showed significantly higher smoking prevalence than their counterparts with good school achievement (44.7\% vs. $12.7 \%$, respectively, $\chi_{(1)}^{2}=176.600, p<0.001$ ).

There was no significant difference by gender in the mean BMI (for boys mean=20.8, $\mathrm{SD}=4.37$; for girls mean=20.9, $\mathrm{SD}=3.94$; $\mathrm{W}_{(1327)}=0.380, \mathrm{p}=0.704$; Cohen $\mathrm{d}=0.02$ ). Based on BMI, $24.0 \%$ of all students were overweight or at risk of becoming overweight, and $8.7 \%$ were underweight. The prevalence of nutritional catego- ries was similar by gender $\left(\chi_{(2)}^{2}=1.926, \mathrm{p}=0.382\right)$. However, there was a significant gender difference in the proportion of perceived weight status $\left(\chi_{(2)}^{2}=23.809, \mathrm{p}<0.001\right)$. More than one third of girls considered themselves to be overweight compared to almost one quarter of boys. Girls reported significantly more frequently a desire to lose weight $\left(\chi_{(2)}^{2}=69.036, p<0.001\right)$ than boys. Similar frequency of smoking were presented in adolescents whose goal was either to lose or gain weight $(27.8 \%$ vs. $29.5 \%)$ and data were considerably lower among those who were satisfied with their body shape $\left(18.7 \% ; \chi_{(2)}^{2}=16.566, \mathrm{p}<0.001\right)$. The odds ratio of dieting was almost two times higher among girls compared to boys $\left(\chi_{(1)}^{2}=13.617, \mathrm{p}<0.001 ; \mathrm{OR}=1.81,95 \%\right.$ CI 1.32-2.49, $\left.\mathrm{p}<0.001\right)$.

Factors associated with smoking: The results of bivariate and multivariate logistic regression analyses were similar; however, the strength of interrelations lessened considerably (Table 2). In multivariate models conducted separately by gender, the belief that smoking controls weight increased the odds of smoking in the past 30 days by $70 \%$ for girls. Higher grade was a remarkable risk factor for smoking in both gender (for boys $\mathrm{OR}=5.94,95 \%$ CI 2.75-12.86, $\mathrm{p}<0.001$; for girls $\mathrm{OR}=5.00,95 \%$ CI 2.28-11.00, $\mathrm{p}<0.001)$. Students' odds of smoking who reported that one or both of their parents were smoking increased almost two times for boys and almost three times for girls. Smoking friends proved to be the most serious risk factor (for boys $\mathrm{OR}=6.35,95 \%$ CI 2.56-15.74, $\mathrm{p}<0.001$; for girls $\mathrm{OR}=10.87,95 \%$ CI $4.18-28.22, \mathrm{p}<0.001)$. Satisfactory or poorer school achievement increased three times and four times the odds of smoking for boys and girls, respectively. In bivariate models higher BMI significantly increased the odds of smoking in both gender (for boys $\mathrm{OR}=1.07,95 \%$ CI 1.03-1.11, $\mathrm{p}=0.001$; for girls $\mathrm{OR}=1.07,95 \% \mathrm{CI} 1.03-1.12, \mathrm{p}<0.001$ ) whereas in multivariate models the significant explanatory power of BMI was lost.

The mediator role of smoking's weight control belief in the association between BMI and smoking: series of binary logistic regression analyses were conducted to examine the potential mediator role of weight control belief of smoking related to the association between BMI and smoking. The BMI showed significant association with smoking controlled for gender and grade $(\mathrm{OR}=1.04,95 \%$ CI $1.01-1.07, \mathrm{p}=0.013)$, likewise the belief that smoking controls weight predicted increased odds of smoking $(\mathrm{OR}=1.96,95 \%$ CI 1.49-2.58, $\mathrm{p}<0.001)$. However, when weight control belief of smoking was entered into the model, BMI lost its significant explanatory power for smoking ( $\mathrm{OR}=1.03,95 \%$ CI $0.99-1.06, \mathrm{p}=0.111$ ). This result supports that the belief that smoking controls weight plays a mediator role in the association between BMI and smoking (Fig. 1).

Factors associated with the belief that smoking controls weight: predictor variables of smoking's weight control belief (gender, grade, objective BMI, perceived body shape, dieting, parental smoking, smoking friends) were tested with binary logistic regression analyses (Table 3 ). In bivariate models all predictor variables except dieting and parental smoking showed significant association with the weight control belief of smoking. In the multivariate model the odds of higher agreement with the weight controlling effect of smoking increased significantly among students who perceived themselves as overweight $(\mathrm{OR}=1.63,95 \%$ CI $1.20-2.21, \mathrm{p}=0.002)$ and were older $(9$ th grade, $\mathrm{OR}=1.42,95 \% \mathrm{CI} 1.07-1.89, \mathrm{p}=0.016)$, and the odds of higher agreement increased tendentiously among girls $(\mathrm{OR}=1.27$, 
Table1. Characteristics of the sample

\begin{tabular}{|c|c|c|c|}
\hline & $\begin{array}{c}\text { Girls } \\
\mathrm{n}=792\end{array}$ & $\begin{array}{c}\text { Boys } \\
\mathrm{n}=653\end{array}$ & $\begin{array}{c}\text { Total } \\
n=1445\end{array}$ \\
\hline $\begin{array}{l}\text { Grade }(\%) \\
\text { 6th } \\
9 \text { th }\end{array}$ & $\begin{array}{l}47.9 \\
58.9\end{array}$ & $\begin{array}{l}52.1 \\
41.1\end{array}$ & $\begin{array}{l}37.2 \\
62.8\end{array}$ \\
\hline $\begin{array}{l}\text { Smoking status (\%) } \\
\text { Smoker }\end{array}$ & 26.3 & 23.1 & 24.8 \\
\hline $\begin{array}{l}\text { Smoking quantity (\%) } \\
\leq 1 \text { cigarette } \\
2-5 \text { cigarettes } \\
6-20 \text { cigarettes } \\
\geq 20 \text { cigarettes }\end{array}$ & $\begin{array}{c}27.3 \\
32.7 \\
34.6 \\
5.4\end{array}$ & $\begin{array}{l}21.5 \\
26.2 \\
42.3 \\
10.1\end{array}$ & $\begin{array}{l}24.9 \\
29.9 \\
37.9 \\
7.3\end{array}$ \\
\hline $\begin{array}{l}\text { Parental smoking }(\%) \\
\text { One or both parent(s) smoked }\end{array}$ & 51.0 & 47.9 & 49.6 \\
\hline $\begin{array}{l}\text { Smoking friends }(\%)^{*} \\
\text { One or more }\end{array}$ & 67.1 & 61.8 & 64.7 \\
\hline $\begin{array}{l}\text { Agreement with the belief smoking controls weight }(\%)^{* *} \\
\text { High agreement }\end{array}$ & 53.3 & 45.8 & 50.0 \\
\hline $\begin{array}{l}\text { Self-reported family income }(\%)^{* * *} \\
\text { Poor }\end{array}$ & 10.3 & 5.2 & 8.0 \\
\hline $\begin{array}{l}\text { School achievement }(\%)^{* * *} \\
\text { Satisfactory or worse }\end{array}$ & 32.8 & 43.0 & 37.4 \\
\hline $\begin{array}{l}\text { BMl based on measured data } \\
\text { Mean (SD) }\end{array}$ & $20.9(3.94)$ & $20.8(4.37)$ & $20.9(4.13)$ \\
\hline $\begin{array}{l}\text { Nutritional status based on measured data (\%) } \\
\text { Underweight } \\
\text { Normal } \\
\text { Overweight }\end{array}$ & $\begin{array}{l}9.1 \\
68.3 \\
23.6\end{array}$ & $\begin{array}{l}8.1 \\
66.3 \\
25.6\end{array}$ & $\begin{array}{l}8.7 \\
67.3 \\
24.0\end{array}$ \\
\hline $\begin{array}{l}\text { Perceived body shape }(\%)^{* * *} \\
\text { Thin } \\
\text { About right size } \\
\text { Overweight }\end{array}$ & $\begin{array}{l}14.9 \\
49.4 \\
35.6\end{array}$ & $\begin{array}{l}20.9 \\
55.0 \\
24.1\end{array}$ & $\begin{array}{l}17.6 \\
51.9 \\
30.5\end{array}$ \\
\hline $\begin{array}{l}\text { Weight management goals }(\%)^{* * *} \\
\text { Lose weight } \\
\text { Gain weight } \\
\text { Stay the same weight }\end{array}$ & $\begin{array}{l}52.6 \\
14.8 \\
32.5\end{array}$ & $\begin{array}{l}30.4 \\
22.7 \\
46.9\end{array}$ & $\begin{array}{l}42.7 \\
18.4 \\
39.0\end{array}$ \\
\hline $\begin{array}{l}\text { Dieting }(\%)^{* * *} \\
\text { Yes }\end{array}$ & 17.5 & 10.5 & 14.3 \\
\hline
\end{tabular}

Note: ${ }^{*} p<0.05 ;{ }^{* *} p<0.01 ;{ }^{* * *} p<0.001$

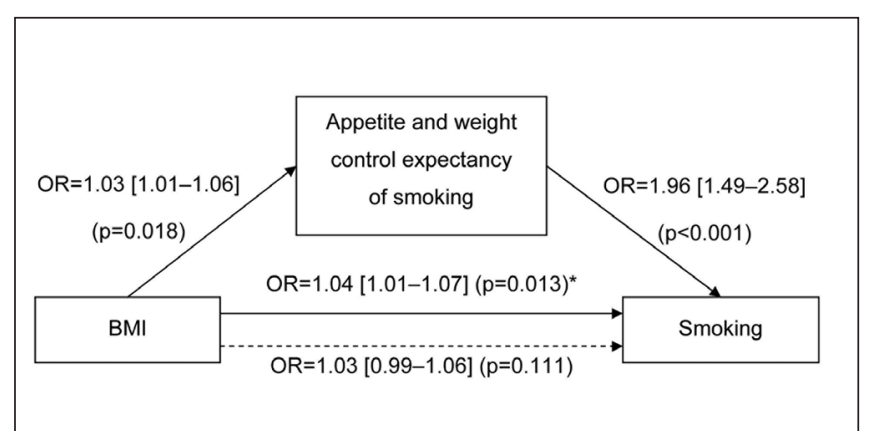

Fig. 1. The mediator role of the belief that smoking supports weight control in the association between BMI and smoking (mediation analysis).

Note: Odds ratios and 95\% confidence intervals are shown in Fig. 1.

*Analysis without the mediator variable. All analyses were conducted controlling for gender and grade.
95\% CI 1.00-1.61, $\mathrm{p}=0.051)$. In addition, the belief that smoking supports weight control showed weak, but significant correlation with the number of cigarettes smoked per day in the group of smokers $\left(r_{s}=0.26, p=0.001\right)$.

\section{DISCUSSION}

This study examined factors associated with smoking and belief about weight control effect of smoking in a population based, cross-sectional sample of Hungarian metropolitan adolescents. The prevalence of current smoking among 6th graders resembled the latest population data of Hungarian adolescents from similar age group (3). Nevertheless, smoking rate was higher among 9th graders in our sample than findings from other studies (3-6). In 
Table 2. Factors associated with smoking

\begin{tabular}{|c|c|c|c|c|}
\hline \multirow{3}{*}{ Variables } & \multicolumn{2}{|c|}{ Bivariate association } & \multicolumn{2}{|c|}{ Multivariate model } \\
\hline & Boys & Girls & Boys ( $n=467$ ) & Girls (n=630) \\
\hline & OR $(95 \% \mathrm{Cl})$ & OR $(95 \% \mathrm{Cl})$ & OR $(95 \% \mathrm{Cl})$ & $\mathrm{OR}(95 \% \mathrm{Cl})$ \\
\hline Objectively overweight & $1.07^{\star *}(1.03-1.11)$ & $1.07^{\star \star *}(1.03-1.12)$ & $1.00(0.93-1.08)$ & $1.03(0.97-1.10)$ \\
\hline $\begin{array}{l}\text { Body shape perceived as } \\
\text { overweight }\end{array}$ & $0.94(0.61-1.46)$ & $1.24(0.89-1.74)$ & $0.88(0.41-1.90)$ & $0.73(0.42-1.25)$ \\
\hline Dieting & $1.27(0.71-2.26)$ & $1.22(0.81-1.86)$ & $1.40(0.57-3.45)$ & $0.92(0.51-1.66)$ \\
\hline $\begin{array}{l}\text { Agreement with the belief } \\
\text { that smoking controls weight }\end{array}$ & $1.83^{\star *}(1.25-2.67)$ & $2.35^{\star \star *}(1.66-3.33)$ & $1.61^{+}(0.99-2.62)$ & $1.70^{*}(1.08-2.65)$ \\
\hline 9th grade & $11.03^{\star * \star}(6.19-19.64)$ & $8.43^{\star * \star}(4.93-14.41)$ & $5.94^{\star * *}(2.75-12.86)$ & $5.00^{* * *}(2.28-11.00)$ \\
\hline $\begin{array}{l}\text { One or both parent(s) } \\
\text { smoked }\end{array}$ & $2.24^{* \star *}(1.54-3.27)$ & $2.93^{\star \star \star}(2.09-4.12)$ & $1.92^{*}(1.17-3.16)$ & $2.94^{\star \star \star}(1.89-4.57)$ \\
\hline One or more smoking friends & $22.18^{\star \star \star}(9.61-51.18)$ & $31.95^{\star \star *}(12.96-78.77)$ & $6.35^{\star * *}(2.56-15.74)$ & $10.87^{* * *}(4.18-28.22)$ \\
\hline Poor school achievement & $5.23^{* * *}(3.46-7.92)$ & $6.32^{\star * *}(4.43-9.01)$ & $3.00^{* * *}(1.79-5.01)$ & $4.03^{\star \star \star}(2.62-6.20)$ \\
\hline Poor family income & $1.66(0.79-3.52)$ & $1.29(0.78-2.14)$ & $3.09^{*}(1.06-9.00)$ & $1.36(0.68-2.74)$ \\
\hline $\mathrm{R}^{2}$ (Nagelkerke) & - & - & $41.5 \%$ & $43.9 \%$ \\
\hline
\end{tabular}

Note: ${ }^{*} p<0.1 ;{ }^{*} p<0.05 ;{ }^{* *} p<0.01 ;{ }^{* * *} p<0.001$

Table 3. Factors associated with the belief that smoking controls weight

\begin{tabular}{|l|c|c|}
\hline \multirow{2}{*}{ Variables } & Bivariate association & Multivariate model \\
\cline { 2 - 3 } & OR $(95 \% \mathrm{Cl})$ & $1.27^{+}(1.00-1.61)$ \\
\hline Girls & $1.35^{* *}(1.08-1.69)$ & $1.42^{*}(1.07-1.89)$ \\
\hline 9th grade & $1.54^{* * *}(1.23-1.94)$ & $1.03(0.85-1.26)$ \\
\hline Objectively overweight & $1.21^{*}(1.03-1.41)$ & $1.63^{* *}(1.20-2.21)$ \\
\hline Body shape perceived as overweight & $1.62^{* * *}(1.27-2.07)$ & $0.90(0.62-1.30)$ \\
\hline Dieting & $1.30^{+}(0.95-1.78)$ & $1.10(0.87-1.39)$ \\
\hline One or both parent(s) smoked & $1.22^{+}(0.98-1.52)$ & $1.17(0.88-1.57)$ \\
\hline One or more smoking friends & $1.54^{* * *}(1.22-1.95)$ & $4.0 \%$ \\
\hline$R^{2}$ (Nagelkerke) & - & \\
\hline
\end{tabular}

Note: ${ }^{*} p<0.1 ;{ }^{*} p<0.05 ;{ }^{* *} p<0.01 ;{ }^{* * *} p<0.001$

agreement with the literature suggesting that social influences are the most important determinants of adolescent smoking, we supported that smoking friends and the parents' smoking predicted most likely current smoking $(7,40,41)$. Poor academic achievement in school had also a great impact on adolescents' cigarette consumption. Our findings are consistent with the literature, inasmuch social and school factors are key elements in adolescent smoking $(7,40-42)$.

The relevant literature indicates discrepancies for relationship between BMI and smoking. Some evidence indicates a positive association between smoking and body weight while others have found this unrelated (8). The current study found significant positive interrelation between BMI based on measured data and smoking. According to our results, the belief that smoking controls weight plays a mediator role in the above interrelation. Thus it can contribute to resolve inconsistencies of findings published in the literature about the association of BMI and smoking. Otherwise, it indicates the significance of considering cognitive factors.
Many recent studies examined overweight perception and youth smoking and most of them found that perceived overweight in adolescence is a risk factor for smoking, but the pattern of findings by gender is rather unclear $(13,17,18,21,23-28)$. Actual dieting behaviour showed a stronger relationship with smoking and it was found to be more specific for females than males $(8,29,30)$. According to our results, perception of overweight like the dieting behaviour did not indicate any association with adolescent smoking in univariate or multivariate analyses. Previous researches provided some evidence for that the belief smoking supports weight control is more prevalent among smokers than non-smokers. The association of this finding with gender is inconsistent because some studies reported the absence of gender difference while others found a stronger association among females $(8,12,13,15,18,38)$. In our study both girls and boys had increased risk of being current smoker based on the belief smoking controls weight.

Independent of the smoking status, the whole sample was examined to identify other factors associated with the belief that 
smoking controls weight. The endorsement of this belief seems to be gender specific and age related among youth because girls and older adolescents believed that smoking can help control body weight. Our result by gender is consistent with prior studies that compared the endorsement of appetite-weight control expectancies of smoking (38). The association of the belief and age is in concordance with the findings of Boles et al. except that non-smokers as well as smokers come to believe that smoking controls weight as youth move through adolescence (13). A possible explanation for the belief's association with gender and age could be the change in body shape during adolescence and when body fat begins to be deposited the issue of weight may become more pressing for adolescent girls (13). The literature supports evidence for the positive association between perceived overweight and adolescent smoking initiation or maintenance (8). The current study identified that agreement with the weight control belief of smoking was significantly higher among overweight participants and this result was similar regarding the subjective or objective determination of overweight.

The present study is the first to document the interrelation between body-weight related factors and smoking among Hungarian adolescents. In addition, we indentified that the belief of smoking supporting weight control plays a mediator role in the association of BMI and smoking. Furthermore, the slightly investigated weight controlling belief of smoking among adolescent population was also explored.

There are some limitations that must be considered. First, this study is cross-sectional thus the level of causal inference is low, but since it is an ongoing cohort study we have the possibility to build up a predictive model to infer the real causation. Second, the present sample is limited only to urban adolescents therefore it cannot be extended to rural adolescents. Third, sampling procedure was confidential but not anonymous given the longitudinal design of the research. Thus a potential bias is related to selfreported smoking behaviour. A prior research indicates that many adolescent smokers underestimate the amount of cigarettes they smoke or even deny smoking (43). Adolescents' disclosure of cigarette smoking is also different when adolescents are promised confidentiality without anonymity compared to when the confidentiality is coupled with anonymity (43). However, other studies found that the concordance between self-reported smoking status and serum cotinine levels was above $90 \%(23,44)$.

The results of the present study emphasize the widespread belief in weight control effect of tobacco smoking and that many adolescents try to lose weight. The epidemic of overweight and obesity is observed among Hungarian adolescents, with higher than average BMI compared to other European countries (10). Weight management goals and weight loss attempts are especially emphasized among females at the end of adolescence and in early adulthood. This period intensifies the belief that smoking may have a weight control effect $(13-18,29,45,46)$. Our results indicate that overweight youth are more prone to use tobacco for weight management which may later lead to regular smoking (11, $15,17,47,48)$. Generally, adolescents with weight concerns, especially females, are more vulnerable to tobacco advertising targeted on youth. Thus, pro-tobacco advertising remains a key issue for tobacco industry, despite its total ban in Hungary $(29,49,50)$.

Dispelling the belief that smoking controls weight must be a key element of tobacco prevention programmes for adolescents while encouraging healthy methods of weight management. Routine, well-balanced and nutritious meals control body weight and are protective against regular overeating (51). Based on prior studies, skipping breakfast regularly was associated with other unhealthy eating habits and harmful health behaviours such as smoking (52). As this study is the first in Hungary to document interrelations of smoking and body-weight related beliefs among adolescents additional research is warranted. Yet, highlighting the precautionary principle, it is advisable that dissemination of the key findings is warranted especially to professionals engaged in primary prevention programmes (physicians, public health workforce, health visitors, school nurses). Implementation could be achieved integrating tobacco prevention and cessation education into regular professional training and ongoing professional education opportunities. Finally, this knowledge should be incorporated in messages of school-based, anti-tobacco programmes.

\section{Acknowledgement:}

The authors thank Róbert Urbán PhD for assistance in manuscript preparation.

\section{Conflict of Interests Statement:}

None declared.

\section{Sponsorship:}

This research project was supported by the Fogarty International Center, the National Cancer Institute, and the National Institute of Drug Abuse (1 R01 TW007927-01, PI: Kristie Foley, PhD; Co-PI Péter Balázs, MD, $\mathrm{PhD})$.

\section{Statement on the Ethical Conduct of Research:}

All consent documents and research protocols/study procedures were approved by the Semmelweis University Regional and Institutional Committee of Science and Research Ethics.

\section{REFERENCE}

1. World Health Organization. Highlights on health in Hungary 2005 [Internet]. Geneva: WHO; 2006 [cited 2011 Sep 21]. Available from: http:// www.euro.who.int/_data/assets/pdf_file/0016/103219/E88736.pdf.

2. Tombor I, Paksi B, Urbán R, Kun B, Arnold P, Rózsa S, et al. Epidemiology of smoking in the Hungarian population, based on national representative data. Clin Exp Med J. 2011 Mar;5(1):27-37.

3. Halmai R, Németh Á. Tobacco Smoking. In: Németh Á, Költő A, editors. Young people's health and lifestyle 2010. Health Behaviour in Schoolaged Children (HBSC) study: a WHO-collaborative cross-national study national report 2010 [Internet]. Budapest: National Institute of Child Health; 2011. p. 35-9 [cited 2011 Sep 24]. Available from: http://www. ogyei.hu/anyagok/HBSC_2010.pdf. (In Hungarian.)

4. Hibell B, Guttormsson $\bar{U}$, Ahlström S, Balakireva O, Bjarnason T, Kokkevi A, et al. The 2007 ESPAD report: substance use among students in 35 European countries [Internet]. Stockholm: The Swedish Council for Information on Alcohol and Other Drugs; 2009 [cited 2010 Mar 22]. Available from: http://www.espad.org/documents/Espad/ESPAD_reports/2007/The_2007_ESPAD_Report-FULL_091006.pdf.

5. Demjén T, Kiss J, Bőti E, Lörik E, Papp N, Kovács D. Global youth tobacco survey 2008, Hungary [Internet]. Budapest: National Institute for Health Development; 2009 [cited 2010 Jan 25]. Available from: http:// mek.oszk.hu/07900/07959/07959.pdf. (In Hungarian.)

6. Urbán R. Smoking outcome expectancies mediate the association between sensation seeking, peer smoking, and smoking among young adolescents. Nicotine Tob Res. 2010 Jan;12(1):59-68. 
7. Tyas SL, Pederson LL. Psychosocial factors related to adolescent smoking: a critical review of the literature. Tob Control. 1998;7(4):409-20.

8. Potter BK, Pederson LL, Chan SS, Aubut JA, Koval JJ. Does a relationship exist between body weight, concerns about weight, and smoking among adolescents? An integration of the literature with an emphasis on gender. Nicotine Tob Res. 2004 Jun;6(3):397-425.

9. Currie C, Roberts C, Morgan A, Smith R, Settertobulte W, Samdal O, et al. Young people's health in context. Health Behaviour in School-aged Children (HBSC) study: international report from the 2001/2002 survey [Internet]. Copenhagen: WHO Regional Office for Europe [cited 2011 Sep 19]. Available from: http://www.hbsc.org/downloads/IntReport04/ Part1.pdf.

10. Németh Á. Body image, body weight and weight control. In: Németh Á, Költö A, editors. Young people's health and lifestyle 2010. Health Behaviour in School-aged Children (HBSC) study: a WHO-collaborative cross-national study national report 2010 [Internet]. Budapest: National Institute of Child Health; 2011. p. 77-82 [cited 2011 Sep 24]. Available from: http://www.ogyei.hu/anyagok/HBSC_2010.pdf. (In Hungarian.)

11. Klesges RC, Robinson LA, Zbikowski SM. Is smoking associated with lower body mass in adolescents? A large-scale biracial investigation. Addict Behav. 1998 Jan-Feb;23(1):109-13.

12. Bean MK, Mitchell KS, Speizer IS, Wilson DB, Smith BN, Fries EA Rural adolescent attitudes toward smoking and weight loss: relationship to smoking status. Nicotine Tob Res. 2008 Feb;10(2):279-86.

13. Boles SM, Johnson PB. Gender, weight concerns, and adolescent smoking. J Addict Dis. 2001;20(2):5-14.

14. Camp DE, Klesges RC, Relyea G. The relationship between body weight concerns and adolescent smoking. Health Psychol. 1993 Jan;12(1):24-32.

15. Cavallo DA, Duhig AM, McKee S, Krishnan-Sarin S. Gender and weigh concerns in adolescent smokers. Addict Behav. 2006 Nov;31(11):2140-6.

16. Caria MP, Bellocco R, Zambon A, Horton NJ, Galanti MR. Overweight and perception of overweight as predictors of smokeless tobacco use and of cigarette smoking in a cohort of Swedish adolescents. Addiction. 2009 Apr; 104(4):661-8.

17. Cawley J, Markowitz S, Tauras J. Lighting up and slimming down: the effects of body weight and cigarette prices on adolescent smoking initiation. J Health Econ. 2004 Mar;23(2):293-311.

18. Seo DC, Jiang N, Kolbe LJ. Association of smoking with body weight in US high school students, 1999-2005. Am J Health Behav. 2009 MarApr;33(2):202-12.

19. Weiss JW, Merrill V, Gritz ER. Ethnic variation in the association between weight concern and adolescent smoking. Addict Behav. 2007 Oct;32(10):2311-6.

20. Kaufman AR, Augustson EM. Predictors of regular cigarette smoking among adolescent females: does body image matter? Nicotine Tob Res 2008 Aug; $10(8): 1301-9$

21. Leatherdale ST, Wong SL, Manske SR, Colditz GA. Susceptibility to smoking and its association with physical activity, BMI, and weight concerns among youth. Nicotine Tob Res. 2008 Mar;10(3):499-505.

22. O'Loughlin J, Karp I, Henderson M, Gray-Donald K. Does cigarette use influence adiposity or height in adolescence? Ann Epidemiol. 2008 May;18(5):395-402.

23. Strauss RS, Mir HM. Smoking and weight loss attempts in overweight and normal-weight adolescents. Int J Obes Relat Metab Disord. 2001 Sep;25(9):1381-5.

24. Winter AL, de Guia NA, Ferrence R, Cohen JE. The relationship between body weight perceptions, weight control behaviours and smoking status among adolescents. Can J Public Health. 2002 Sep-Oct;93(5):362-5.

25. Kendzor DE, Copeland AL, Stewart TM, Businelle MS, Williamson DA Weight-related concerns associated with smoking in young children. Addict Behav. 2007 Mar;32(3):598-607.

26. Koval JJ, Pederson LL, Zhang X, Mowery P, McKenna M. Can young adult smoking status be predicted from concern about body weight and self-reported BMI among adolescents? Results from a ten-year cohort study. Nicotine Tob Res. 2008 Sep;10(9):1449-55.

27. Tomeo CA, Field AE, Berkey CS, Colditz GA, Frazier AL. Weight concerns, weight control behaviors, and smoking initiation. Pediatrics. 1999 Oct:104(4 Pt 1):918-24

28. Xie B, Chou CP, Spruijt-Metz D, Reynolds K, Clark F, Palmer PH, et al. Weight perception and weight-related sociocultural and behavioral factors in Chinese adolescents. Prev Med. 2006 Mar;42(3):229-34.

29. French SA, Perry CL, Leon GR, Fulkerson JA. Weight concerns, dieting behavior, and smoking initiation among adolescents: a prospective study. Am J Public Health. 1994 Nov;84(11):1818-20.
30. Lowry R, Galuska DA, Fulton JE, Wechsler H, Kann L. Weight management goals and practices among U.S. high school students: associations with physical activity, diet, and smoking. J Adolesc Health. 2002 Aug;31(2):133-44.

31. Fulkerson JA, French SA. Cigarette smoking for weight loss or control among adolescents: gender and racial/ethnic differences. J Adolesc Health. 2003 Apr;32(4):306-13.

32. Marcelino G, Oliveira JM, Ravasco P, Marques-Vidal P. Weight concerns and weight reduction practices of Portuguese adolescents. Nutr Hosp. 2009 Nov-Dec;24(6):758.

33. Cole TJ, Bellizzi MC, Flegal KM, Dietz WH. Establishing a standard definition for child overweight and obesity worldwide: international survey. BMJ. 2000 May 6;320(7244):1240-3.

34. Cole TJ, Flegal KM, Nicholls D, Jackson AA. Body mass index cut offs to define thinness in children and adolescents: international survey. BMJ. 2007 Jul 28;335(7612):194.

35. Centers for Disease Control and Prevention. Youth risk behavior survey: questionnaires and item rationales [Internet]. Atlanta, GA: CDC; 2011 [cited 2008 Oct 31]. Available from: http://www.cdc.gov/healthyyouth/ yrbs/questionnaire rationale.htm.

36. Lloyd-Richardson EE, Papandonatos G, Kazura A, Stanton C, Niaura R. Differentiating stages of smoking intensity among adolescents: stagespecific psychological and social influences. J Consult Clin Psychol. 2002 Aug;70(4):998-1009.

37. Myers MG, McCarthy DM, MacPherson L, Brown SA. Constructing a short form of the Smoking Consequences Questionnaire with adolescents and young adults. Psychol Assess. 2003 Jun;15(2):163-72.

38. Urbán R, Demetrovics Z. Smoking outcome expectancies: A multiple indicator and multiple cause (MIMIC) model. Addict Behav. 2010 Jun;35(6):632-5.

39. Baron RM, Kenny DA. The moderator-mediator variable distinction in social psychological research: conceptual, strategic, and statistical considerations. J Pers Soc Psychol. 1986 Dec;51(6):1173-82.

40. Piko B. Smoking in adolescence: do attitudes matter? Addict Behav. 2001 Mar-Apr;26(2):201-17

41. Piko BF. Adolescent smoking and drinking: the role of communal mastery and other social influences. Addict Behav. 2006 Jan;31(1):102-14

42. Pikó B. Health awareness in adolescence. Budapest: Akadémiai Kiadó; 2002. (In Hungarian.)

43. Murray DM, Perry CL. The measurement of substance use among adolescents: when is the 'bogus pipeline' method needed? Addict Behav. 1987;12(3):225-33.

44. Luepker RV, Pallonen UE, Murray DM, Pirie PL. Validity of telephone surveys in assessing cigarette smoking in young adults. Am J Public Health. 1989 Feb;79(2):202-4.

45. Charlton A. Smoking and weight control in teenagers. Public Health. 1984 Sep;98(5):277-81.

46. Klesges RC, Elliott VE, Robinson LA. Chronic dieting and the belief that smoking controls body weight in a biracial, population-based adolescent sample. Tob Control. 1997;6(2):89-94.

47. Halek C, Kerry S, Humphrey H, Crisp AH, Hughes JM. Relationship between smoking, weight and attitudes to weight in adolescent schoolgirls. Postgrad Med J. 1993 Feb;69(808):100-6. Erratum in: Postgrad Med J. 1993 Aug;69(814):667.

48. Rees DI, Sabia JJ. Body weight and smoking initiation: evidence from Add Health. J Health Econ. 2010 Sep;29(5):774-7.

49. European Commission. UCP. Hungary. National law. Act no. 48 of 2008 on the basic requirements and certain restrictions applying to commercial advertising activities [Internet]. Brussels: European Commission; 2011 [updated 2011 Jun 10; cited 2012 Feb 5]. Available from: https:// webgate.ec.europa.eu/ucp/public/index.cfm?event=public.country showCountry\& countryID $=\mathrm{HU}$

50. Kaleta D, Usidame B, Polańska K. Tobacco advertisements targeted on women: creating an awareness among women. Cent Eur J Public Health. 2011 Jun;19(2):73-8

51. Cooper Z, Fairburn CG, Hawker DM. Cognitive-behavioral treatment of obesity: a clinician's guide. New York: Guilford Press; 2003.

52. Höglund D, Samuelson G, Mark A. Food habits in Swedish adolescents in relation to socioeconomic conditions. Eur J Clin Nutr. 1998 Nov;52(11):784-9.

Received September 29, 2011 Accepted in revised form January 20, 2012 